Check for updates

The BMJ

Cite this as: $B M J$ 2021;372:n460 http://dx.doi.org/10.1136/bmj.n460 Published: 16 February 2021

\section{Covid:19: Ethnic minority health staff are less likely to take up vaccine, early data show}

\author{
Gareth lacobucci
}

A hospital trust in the Midlands has said that it is working to understand why some of its staff remain unvaccinated against covid-19 after preliminary findings from a study showed that uptake was especially low among doctors and ethnic minority staff.

The analysis, published as a preprint on 13 February, ${ }^{1}$ looked at 19044 staff at the University Hospitals of Leicester NHS Trust who had all been offered a vaccination since 12 December. As of 3 February, 65\% (12 278) had received at least one dose of vaccine. But this masked substantial variation, with $71 \%$ (8147 of 11485 ) of white staff taking up the vaccine, compared with $59 \%$ (2843 of 4863) of South Asian staff and $37 \%$ (499 of 1357) of black staff. Overall, 36\% of the trust's staff are from ethnic minority backgrounds.

Across all staff, take up was lowest among doctors (57\%, 1721 of 3001), and highest among administrative and executive staff (73\%, 2537 of 3465) and healthcare scientists $(73 \%, 634$ of 871$)$.

The authors said that further work was needed to understand why doctors were less likely to take up the vaccine but noted that doctors were the only staff group at the trust in which people from ethnic minorities form the majority. Doctors were also younger as a cohort than other staff so might perceive themselves as being at lower risk.

Study lead Kamlesh Khunti, professor of primary care diabetes and vascular medicine at the University of Leicester and a member of SAGE (Scientific Advisory Group for Emergencies) and Independent SAGE, told The BMJ that the hospital trust had done a "fantastic" job of promoting vaccination to staff through social media and emails and by providing access seven days a week, but he said that building trust required time.

“There wasn't an issue about access for doctors. But there were a lot of issues of trust. Minority populations have been disproportionately affected by covid-19, they feel they haven't been engaged in the decision making, in the vaccination rollout, and some also feel that ethnic minority populations may not have been tested in the randomised control trials, which isn't true."

He added, "I've experienced this with my own staff where there was vaccine resistance. We've spent quite a while talking to them about why this is important and gone over some of the misinformation that has been created, and eventually they have taken the vaccine. They just needed more information, and we need to be supportive of that and not stigmatise people."

The authors added: "These findings have major implications for the delivery of SARS-CoV-2 vaccination programmes, in healthcare workers and the wider population, and should inform the national vaccination programme to prevent the disparities of the pandemic from widening."

University Hospitals of Leicester NHS Trust said that uptake had increased since the data were collected, and-with help from Khunti's team-it is also surveying staff who haven't accepted the vaccine to find out why, and what would help persuade them to take it. "Three in four Leicester hospital staff have now been vaccinated, with uptake rising across all ethnic groups, and others taking up the offer of a jab in their local community," a trust spokesperson said.

David Wrigley, BMA deputy council chair, said, "It is crucial that employers address any underlying reasons or workplace cultures that may be contributing to greater vaccine hesitancy among [ethnic minority] healthcare workers. It is important that ethnic minority staff have access to adequate information and that trusts are effectively monitoring vaccination status amongst staff to see if there are significant discrepancies that need to be rapidly addressed.”

\section{Martin CA, Marshall C, Patel P, et al. Association of demographic and occupational factors with SARS-CoV-2 vaccine uptake in a multi-ethnic UK healthcare workforce: a rapid real world analysis. MedRxiv [preprint]. 2021.} https://www.medrxiv.org/content/10.1101/2021.02.11.21251548v2

This article is made freely available for use in accordance with BMJ's website terms and conditions for the duration of the covid-19 pandemic or until otherwise determined by BMJ. You may use, download and print the article for any lawful, non-commercial purpose (including text and data mining) provided that all copyright notices and trade marks are retained. 